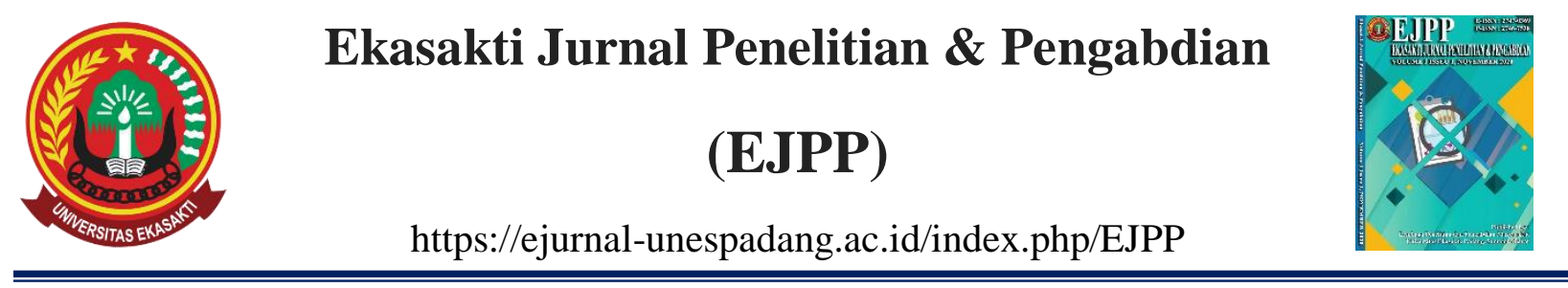

\title{
ANALISA TINGKAT KERUSAKAN PERKERASAN LENTUR PADA RUAS JALAN RAYA LAMBAH MANINJAU KABUPATEN AGAM
}

\author{
Maha Putri Handayani AS, ST.MT ${ }^{1}$ \\ 1) Universitas Ekasakti, Padang \\ Email: mahaputrihandayanias@ gmail.com
}

\section{INFO ARTIKEL}

Received : 18/10/2021

Revised : 28/10/2021

Publish : 11/11/2021

\section{Kata Kunci:}

Indek Kondisi perkerasan,

Kerapatan, Nilai

Pengurang, Nilai

Pengurang Total, Nilai

Pengurang Terkoreksi.

\section{ABSTRAK}

Jalan raya lambah maninjau banyak ditemukan kerusakan pada perkerasan lenturnya yang dapat menyebabkan ketidaknyamanan dan keamanan bagi pengguna jalan, hal tersebut dapat mempengaruhi kondisi arus lalu lintas pada ruas jalan dan dapat berpotensi menimbulkan titik-titik konflik yang akan menghambat pergerakan arus lalu lintas. Tujuan dilakukan penelitian ini adalah untuk mengetahui jenis dan tingkat kerusakan yang terjadi serta menghitung nilai indeks kondisi perkerasan lentur pada ruas jalan raya lambah maninjau Kabupaten Agam ini. Metode yang digunakan untuk mengetahui jenis kerusakan jalan adalah dengan secara visual lapangan mengukur berapa luas masing-masing kerusakan yang terjadi sedangkan untuk menghitung nilai indeks kondisi jalan dengan menggunakan metode pavement conditional indeks (PCI). Dari hasil analisa diperoleh bahwa jenis kerusakan yang didapat adalah berupa retak kulit buaya, retak pinggir, pelapukan dan pelepasan butir, tonjolan dan lengkungan. Sedangkan nilai pavement conditional indeks (PCI) diperoleh sebesar 62 yang berarti bahwa kondisi ruas jalan tersebut termasuk kategori baik (good) untuk dapat di lalui dengan aman..

\section{ABSTRACT}

Keywords:

Pavement Condition

Index, Density,

Subtraction Value, Total

Subtraction Value,

Corrected Subtraction

Value.

\begin{abstract}
The slow maninjau highway has found damage to its flexible pavement which can cause discomfort and safety for road users, it can affect traffic flow conditions on the road and can potentially cause conflict points that will hinder the movement of traffic flow. The purpose of this study was to determine the type and level of damage that occurred and to calculate the index value of the flexible pavement condition on the Lambah Maninjau highway section, Agam Regency. The method used to determine the type of road damage is to visually measure the area of each damage that occurs while to calculate the road condition index value using the pavement conditional index (PCI) method. From the results of the analysis, it was found that the types of damage obtained were in the form of crocodile skin cracks, edge cracks, weathering and grain release, protrusions and bends. While the pavement conditional index (PCI) value was obtained at 62, which means that the condition of the road segment is in the good category to be passed safely.
\end{abstract}

DOI: https://doi.org/10.31933/ejpp.v2i1.401 


\section{PENDAHULUAN}

Seiring dengan perkembangan zaman, Kabupaten Agam tidak luput dari masalahmasalah, salah satunya adalah masalah geometrik jalan, dengan adanya pembangunan prasarana jalan diharapakan dapat memenuhi kebutuhan transportasi yang ada. Prasarana jalan yang sudah di bangun harus diiringi pula dengan pemeliharaan dan perbaikan yang di lakukan secara berkala karena volume arus lalu lintas tiap tahunnya akan selalu bertambah, ditambah dengan tonase jumlah kendaraan berat yang melewatinya serta kondisi tanah yang ada. Tujuan dilakukannya penelitian ini adalah untuk untuk mengetahui jenis dan tingkat kerusakan yang terjadi serta menghitung nilai indeks kondisi perkerasan lentur pada ruas jalan raya lambah maninjau Kabupaten Agam ini.

Menurut UU Nomor 22 Tahun 2009, menerangkan bahwa jalan adalah seluruh bagian jalan, bangunan pelengkap serta perlengkapannya yang ditujukan untuk lalu lintas umum, berada di atas permukaan tanah, di bawah permukaan tanah atau air, serta di atas permukaan air, terkecuali untuk jalan rel serta jala kabel. Kerusakan pada konstruksi perkerasan jalan dapat disebabkan oleh: (1). Lalu lintas, yang dapat berupa peningkatan beban dan repetisi beban; (2). Air, yang dapat berasal dari air hujan, sistem drainase jalan yang tidak baik, naiknya air akibat sifat kapilaritas; (3). Material konstruksi perkerasan. Dalam hal ini dapat disebabkan oleh sifat material itu sendiri atau dapat pula disebabkan oleh sistem pengolahan bahan yang tidak baik; (4). Iklim, Indonesia beriklim tropis dimana suhu udara dan curah hujan umumnya tinggi, yang dapat merupakan salah satu penyebab kerusakan jalan; (5). Kondisi tanah dasar yang tidak stabil. Kemungkinan disebabkan oleh sistem pelaksanaan yang kurang baik, atau dapat juga disebabkan oleh sifat tanah dasarnya yang memang jelek.

Jenis-jenis kerusakannya sebagai berikut:

1. Retak kulit buaya (alligator cracking)

Retak kulit buaya adalah serangkaian retak memanjang paralel yang membentuk banyak sisi menyerupai kulit buaya. Retak ini disebabkan oleh kelelahan akibat beban lalulintas berulang-ulang.Retak dimulai dari bagian bawah permukaan aspal (ataua pondasi yang di stabilisasi).

2. Kegemukan (bleeding)

Kegemukan adalah hasil dari aspal pengikat yang berlebihan, yang bermigrasi ke atas permukaan perkerasan. Kelebihan kadar aspal atau terlalu rendahnya kadar udara dalam campuran, dapat mengakibatkan kegemukan.

3. Retak blok (block cracking)

Retak blok ini berbentuk blok-blok besar yang saling bersambungan, dengan ukuran sisi blok 0,3 sampai $3 \mathrm{~m}$ dan dapat membentuk sudut atau pojok yang tajam. Kerusakan ini disebabkan oleh perubahan volume di dalam campuran aspal atau di dalam lapis pondasi (base) atau tanah dasar. 
4. Tonjolan dan lengkungan (bump and sags)

Tonjolan adalah gerakan atau perpindahan ke atas, bersifat lokal dan kecil dari permukaan perkerasan aspal. Kerusakan disebabkan oleh perkerasan yang tidak stabil.

5. Keriting (corrugation)

Keriting atau bergelombang adalah kerusakan akibat terjadinya deformasi plastis yang menghasilkan gelombang-gelombang melintang atau tegak lurus arah perkerasan.

6. Amblas (depressions)

Amblas adalah penurunan perkerasan yang terjadi pada area terbatas yang mungkin dapat diikuti dengan retakan.

7. Retak refleksi sambungan (joint reflection cracking)

Kerusakan ini umumnya terjadi pada permukaan perkerasan aspal yang telah dihamparkan di atas perkerasan beton.Retak terjadi pada lapis tambahan (overlay) aspal yang mencerminkan pola retak dalam perkerasan beton lama yang berada dibawahnya.

8. Penurunan bahu jalan (lane/shoulder drop off)

Penurunan bahu jalan adalah beda elevasi antara tepi perkerasan dan bahu jalan. Bahu jalan turun relatif terhadap pinggir perkerasaan hal ini tidak di pertimbangkan penting bila selisih tinggi bahu dan perkerasan kurang dari $10-15 \mathrm{~mm}$.

9. Retak memanjang/melintang (longitudinal/transverse cracking)

Retak berbentuk memanjang pada perkerasan jalan, dapat terjadi dalam bentuk tunggal atau berderet yang sejajar dan kadang-kadang sedikit bercabang. Retak melintang merupakan retak tunggal (tidak bersambungan satu sama lain) yang melintang perkerasan.

10. Tambalan dan galian utilitas (patching and utility cut patching)

Tambalan adalah penutupan bagian perkerasan yang mengalami perbaikan.

11. Pengausan (polished aggregate)

Pengausan adalah licinnya bagian perkerasan, akibat ausnya agregat di permukaan.

12. Lubang (potholes)

Lubang adalah lekukan permukaan perkerasan akibat hilangnya lapisan aus dan material lapis pondasi. Lubang bisa terjadi akibat galian utilitas atau tambalan di area perkerasan yang telah ada.

13. Persilangan jalan rel (railroad crossing)

Kerusakan pada persilangan jalan rel dapat berupa amblas atau tonjolan di sekitar dan atau antara lintasan rel.

14. Alur (rutting)

Alur adalah deformasi permukaan perkerasan aspal dalam bentuk turunnya perkerasan ke arah memanjang pada lintasan roda kendaraan. 


\section{Sungkur (shoving)}

Sungkur adalah perpindahan permanen secara lokal dan memanjang dari permukaan perkerasan yang disebabkan oleh beban lalu lintas. Sungkur biasanya terjadi pada perkerasan aspal yang berbatasan dengan perkerasan beton.

16. Retak selip (slippage cracking)

Retak selip atau retak yang berbentuk bulan sabit yang diakibatkan oleh gaya-gaya horizontal yang berasal dari kendaraan.

17. Pengembangan (swell)

Pengembangan adalah gerakan lokal ke atas dari perkerasan akibat pengembangan (pembekuan air) dari tanah dasar atau dari bagian struktur perkerasan.

18. Pelapukan dan pelepasan butir (weathering and raveling)

Pelapukan dan pelepasan butir adalah disintegrasi permukaan perkerasan aspal melalui pelepasan partikel agregat yang berkelanjutan, berawal dari permukaan perkerasan menuju ke bawah atau dari tepi ke dalam.

Metode Pavement Condition Index (PCI) atau Indeks Kondisi Perkerasan yang dikembangkan oleh U.S Army Corp of Engineer adalah sistem penilaian kondisi perkerasan jalan. Dalam metode PCI, 3 faktor utama yang digunakan yaitu: tipe kerusakan, tingkat keparahan kerusakan jumlah atau kerapatan kerusakan (Shahin, 1994). Penilaian terhadap kondisi perkerasan jalan merupakan aspek yang paling penting dalam hal menentukan kegiatan pemeliharaan dan perbaikan jalan, untuk melakukan penilaian kondisi perkerasan jalan tersebut, terlebih dahulu perlu ditentukan jenis kerusakan, penyebab, serta tingkat kerusakan yang terjadi.

Nilai PCI ini memiliki rentang 0 (nol) sampai 100 (seratus) dengan kriteria sempurna (excellent), sangat baik (very good), baik (good), sedang (fair), jelek (poor), sangat jelek (very poor), dan gagal (failed).

a. Jenis-Jenis Kerusakan Perkerasan Jalan.

Menurut Hardiyatmo (2007) yang menerangkan bahwa jenis kerusakan pada perkerasan jalan ada 18 macam.

b. Tingkat Kerusakan (Severity Level)

Severity Level adalah tingkat kerusakan pada tiap-tiap jenis kerusakan. Tingkat kerusakan yang digunakan dalam perhitungan PCI adalah low severity level (L), medium severity level $(\mathrm{M})$, dan high severity level $(\mathrm{H})$.

c. Nilai pengurang (deduct value)

Nilai Pengurang (deduct value) adalah suatu nilai pengurang untuk setiap jenis kerusakan jalan yang diperoleh dari kurva hubungan kerapatan (density) dan tingkat kerapatan (serverity level).

d. Kerapatan (density)

Kerapatan (density) adalah persentase luas atau panjang total dari satu jenis kerusakan terhadap luas atau panjang total bagian jalan yang diukur, bisa dalam $\mathrm{m}^{2}$ atau dalam meter persegi atau meter panjang. Dihitung dengan persamaan:

$$
\text { Kerapatan }\left(\text { density) }(\%)=\frac{A d}{A s} \times 100 \%\right.
$$


Atau

Keterangan:

$$
\text { Kerapatan }(\text { density })(\%)=\frac{L d}{A s} \times 100 \%
$$

$\mathrm{Ad}=$ Luas total dari satu jenis perkerasan untuk setiap tingkat keparahan kerusakan $\left(\mathrm{m}^{2}\right)$

$\mathrm{Ld}=$ Panjang total jenis kerusakan untuk tiap tingkat keparahan kerusakan $\left(\mathrm{m}^{2}\right)$

As $=$ Luas total unit sampel $\left(\mathrm{m}^{2}\right)$.

e. Nilai pengurang total (Total Deduct Value, TDV)

Nilai pengurang total atau TDV adalah jumlah total dari nilai pengurang (deduct value) yang dipakai sebagai tipe faktor pemberat yang telah di indikasikan derajat pengaruh kombinasi tiap jenis kerusakan, dan tingkat keparahan kerusakan yang ada.

f. Menentukan Nilai q

Menentukan nilai q dapat dicari dari berapa kerusakan pada setiap unit sampel, misalkan dalam 1 unit sampel misal $100 \mathrm{~m}$ unit sampel dan terdapat berapa kerusakan jika terdapat 2 kerusakan maka nilai q yang di dapatkan adalah sebanyak 2 buah, nilai q adalah nilai yang mengikuti dari banyak kerusakan pada unit sampelnya. Nilai q diperlukan untuk menarik garis untuk grafik Corrected Deduct Value (CDV).

\section{g. Nilai pengurang terkoreksi (Corrected Deduct Value)}

Nilai pengurang terkoreksi atau CDV diperoleh dari kurva hubungan Antara nilai pengurang total (TDV) dan nilai pengurangan (DV) dengan memilih kurva yang sesuai.

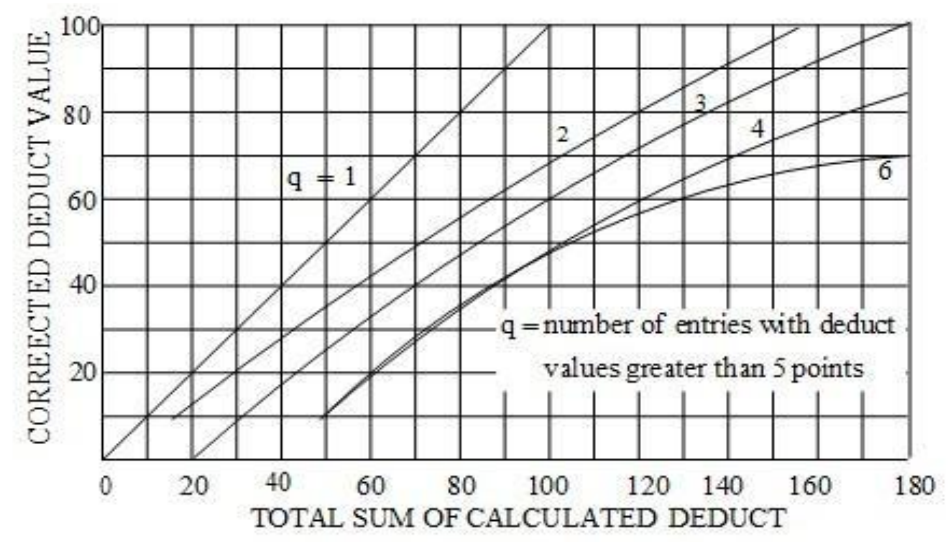

Gambar 1. Penentuan Nilai pengurang terkoreksi atau CDV

Sumber : Direktorat Jenderal Bina Marga, 1995

h. Nilai PCI

Jika nilai CDV telah diketahui, maka nilai PCI untuk setiap unit sampel dapat dihitung dengan menggunakan persamaan:

Keterangan:

$$
P C I S=100-C D V
$$

PCIs = Pavement Condition Index untuk setiap unit sampel atau unit penelitian, 
CDV = Corrected Deduct Value untuk setiap unit sampel.

i. Nilai PCI perkerasan secara keseluruhan pada ruas jalan tertentu dapat dihitung dengan persamaan:

Keterangan:

$$
\text { PCIr }=\frac{P C L S}{N}
$$

$$
\begin{array}{ll}
\text { PCIr } & =\text { Nilai PCI rata-rata dari seluruh area penelitian } \\
\text { PCLs } & =\text { Nilai PCI untuk setiap unit sampel } \\
\mathrm{N} & =\text { Jumlah unit sampel }
\end{array}
$$

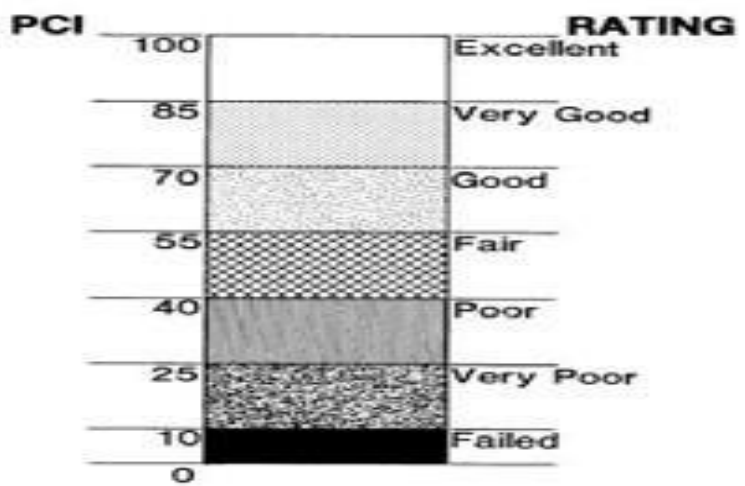

Gambar 2. Nilai kondisi perkerasan dan kondisi kerusakan

Sumber: Direktorat Jenderal Bina Marga, 1995

j. Tipe kerusakan jalan berdasarkan nilai PCI

- $0 \mathrm{~s} / \mathrm{d} 10=$ Gagal $($ Failed $)$

- $11 \mathrm{~s} / \mathrm{d} 25=$ Sangat Buruk (Very Poor)

- $26 \mathrm{~s} / \mathrm{d} 40=$ Buruk $($ Poor $)$

- $41 \mathrm{~s} / \mathrm{d} 55=$ Sedang $($ Fair $)$

- $56 \mathrm{~s} / \mathrm{d} 70=$ Baik $($ Good $)$

- $71 \mathrm{~s} / \mathrm{d} 85=$ Sangat Baik (Very Good)

- $86 \mathrm{~s} / \mathrm{d} 100=$ Sempurna $($ Exellent $)$.

\section{METODE PENELITIAN}

Penelitian ini dilakukan pada ruas jalan raya lambah maninjau Kabupaten Agam sepanjang 2 Km (STA 0+500 - STA 1+500), dimulai dari Gapura Kenagarian Sianok VI Suku sampai dengan persimpangan tiga Taruko Resto, di lakukan selama 2 (dua) hari.

Jenis penelitian yang digunakan dalam penelitian ini menggunakan penelitian kuantitatif. Penelitian ini menggunakan data berupa angka sebagai alat menemukan keterangan mengenai apa yang ingin kita teliti, dan angka-angka yang terkumpul kemudian di analisis.

Pada penelitian kuantitatif menggambarkan dua variabel, yaitu variable bebas (variabel yang variasinya mempengaruhi variabel lain) dan variabel terikat (variabel penelitian yang di ukur untuk mempengaruhi efek atau pengaruh variabel lainnya). 
Data primer, merupakan data yang diperoleh dengan melakukan pengamatan langsung di lapangan. Adapun data primer yang dibutuhkan dalam penelitian ini adalah: data berupa gambar jenis-jenis kerusakan jalan yang di tinjau; data dimensi (panjang, lembar dan kedalaman) masing-masing jenis kerusakan jalan; dan data panjang dan lebar jalan.

Data Sekunder adalah gambaran umum tentang hal-hal yang berkaitan dengan objek dari penelitian yang didapatkan dari pihak ketiga. Data sekunder yang digunakan dalam penelitian ini adalah data jumlah penduduk dan jenis kendaraan yang melewati ruas jalan ini.

Setelah survey selesai dilaksanakan akan didapat sekumpulan data yang akan digunakan dalam perhitungan. Langkah yang akan dilakukan selanjutnya adalah pengolahan terhadap datadata tersebut.

1. Dimulai dari survey, yang di lakukan adalah:

a. Membagi tiap segmen menjadi beberapa unit sampel, pada penelitian ini unit sampel dibagi setiap jarak 100 meter.

b. Menentukan tingkat kerusakan (severity level).

c. Mengukur dimensi kerusakan pada tiap unit sampel.

d. Mencatat hasil pengukuran ke data hasil survei.

2. Analisis kondisi jalan menggunakan metode Pavement Condition Index (PCI), dimulai dari:

a. Menghitung density (kadar kerusakan).

b. Menentukan nilai deduct value tiap jenis kerusakan.

c. Menghitung nilai total deduct value (TDV).

d. Menentukan nilai corrected deduct value (CDV).

3. Menghitung nilai PCI (Pavement Condition Index).

Langkah-langkah yang dilakukan dalam menganalisa data untuk menentukan nilai PCI jalan tersebut adalah sebagai berikut:

a. Menghitung density yang merupakan persentase luasan kerusakan terhadap luasan unit penelitian menggunakan rumus 1 dan 2 .

b. Menghitung nilai pengurangan (deduct value).

c. Menghitung nilai total pengurangan (total deduct value/TDV) untuk masingmasing unit penelitian.

d. Menghitung nilai koreksi nilai pengurangan (corrected deduct value/CDV) untuk masing-masing unit penelitian.

e. Menghitung nilai pavement condition index (PCI) untuk masing-masing unit penelitian, menggunakan rumus 3 dan 4 .

f. Menghitung nilai rata-rata PCI dari semua unit penelitian pada suatu jalan yang diteliti untuk mendapatkan nilai PCI dari jalan.

g. Menentukan kondisi perkerasan jalan dengan menggunakan nilai PCI. 


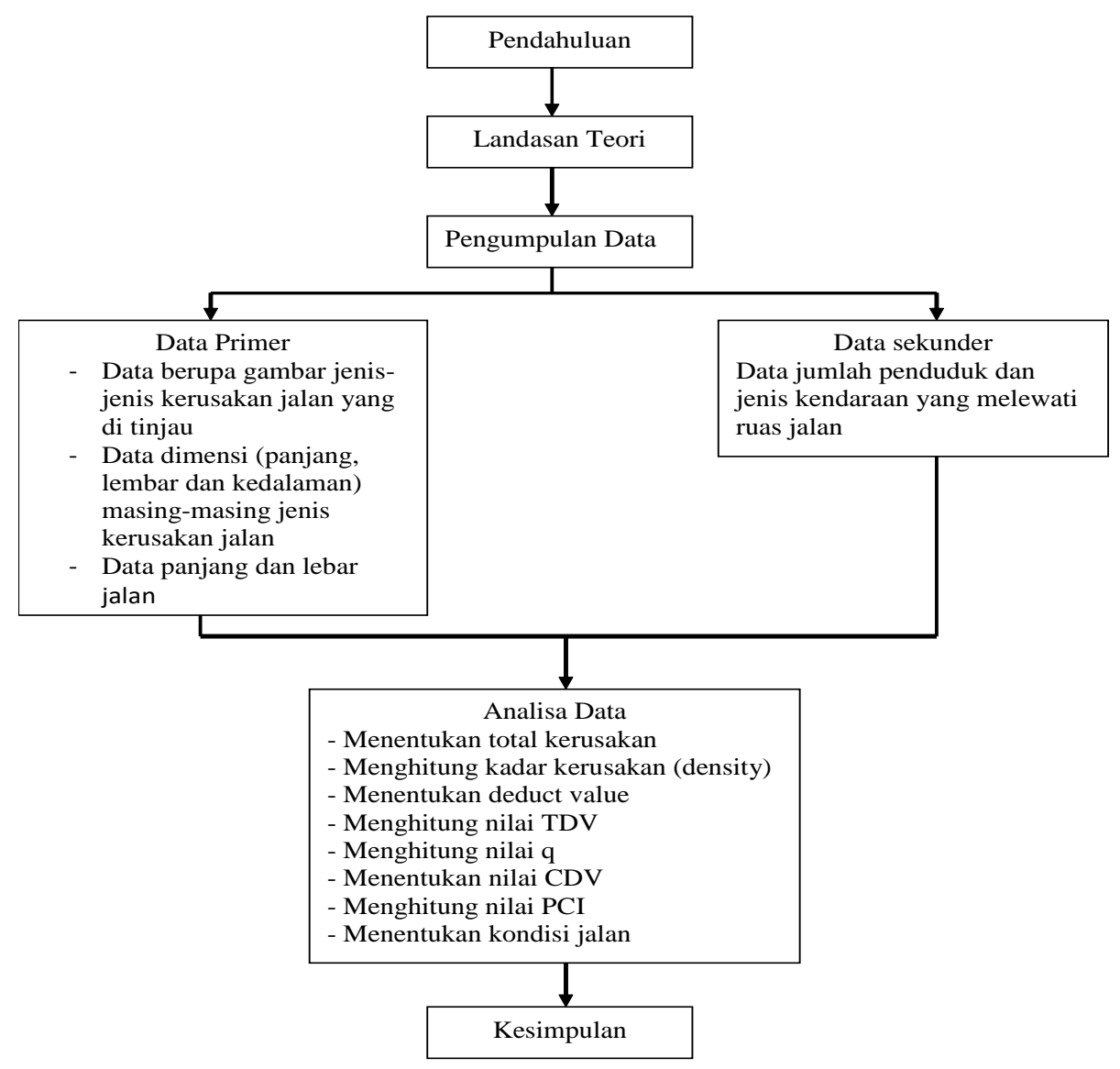

Gambar 4. Bagan Alur Penulisan

\section{HASIL DAN PEMBAHASAN}

\section{Analisa kerusakan jalan}

Adapun data yang didapat dari hasil survey adalah sebagai berikut:

Tabel 1. Hasil survey

\begin{tabular}{|c|c|c|c|c|c|}
\hline \multirow{2}{*}{ No } & \multirow{2}{*}{ STA (M) } & \multirow{2}{*}{ Jenis Kerusakan } & \multicolumn{3}{|c|}{ Dimensi } \\
\hline & & & $\mathbf{P}(\mathbf{M})$ & $\mathbf{L}(\mathbf{M})$ & $\mathbf{A}\left(\mathbf{M}^{2}\right)$ \\
\hline \multirow[t]{2}{*}{1} & STA $0+500 \mathrm{~s} / \mathrm{d}$ STA $0+600$ & Retak kulit buaya & 0,63 & 1,92 & 1,209 \\
\hline & & Lubang & 0,07 & 2,5 & 0,175 \\
\hline \multirow[t]{2}{*}{2} & STA $0+600 \mathrm{~s} / \mathrm{d}$ STA $0+700$ & Tambal & 0,67 & 1,72 & 1,152 \\
\hline & & Pelapukan Pelepasan Butir & 0,67 & 1,26 & 0,844 \\
\hline \multirow[t]{2}{*}{3} & STA $0+700 \mathrm{~s} / \mathrm{d}$ STA $0+800$ & Retak Pinggir & 0,27 & 4,6 & 1,242 \\
\hline & & Tonjolan Dan Lengkungan & 0,91 & 0,64 & 0,582 \\
\hline 4 & STA $0+800 \mathrm{~s} / \mathrm{d}$ STA $0+900$ & Lubang & 1,09 & 0,54 & 0,587 \\
\hline 5 & STA $0+900 \mathrm{~s} / \mathrm{d}$ STA $1+000$ & Lubang & 0,8 & 0,35 & 0,28 \\
\hline 6 & STA $1+000$ s/d STA $1+100$ & Lubang & 0,47 & 0,46 & 0,216 \\
\hline 7 & STA $1+100$ s/d STA $1+200$ & Lubang & 1,08 & 1,69 & 1,853 \\
\hline 8 & STA $1+200 \mathrm{~s} / \mathrm{d}$ STA $1+300$ & Pelepasan Butir & 4,01 & 2,0 & 8,02 \\
\hline 9 & STA $1+300 \mathrm{~s} / \mathrm{d}$ STA $1+400$ & Tambal & 2,2 & 0,99 & 2,178 \\
\hline 10 & STA $1+400$ s/d STA $1+500$ & Lubang & 1,08 & 0,48 & 0,528 \\
\hline
\end{tabular}

Sumber: Hasil Survey, (2020) 
Dari data hasil survey selanjutnya dapat di hitung nilai kerapatan (density) masingmasing dari kerusakan jalan:

a. Retak kulit buaya

Untuk kerusakan retak buaya (sample no 1) total daerah kerusakan $1.2096 \mathrm{~m}^{2}$ dengan luas besar dari $500 \mathrm{~m}^{2}$ maka termasuk kedalam kategori Severity Level adalah $\mathrm{H}$ (high).

$$
\begin{aligned}
& \text { Density }=\frac{A d}{A s} \times 100 \% \\
& \text { Density }=\frac{1.2096}{500} \times 100 \% \\
& \text { Density }=0,24 \%
\end{aligned}
$$

b. Lubang

Untuk kerusakan lubang (sample no 2) total daerah kerusakan $0.175 \mathrm{~m}^{2}$.

$$
\begin{gathered}
\text { Density }=\frac{A d}{A s} \times 100 \% \\
\text { Density }=\frac{0.175}{500} \times 100 \% \\
\text { Density }=0,03 \%
\end{gathered}
$$

Selanjutnya untuk nilai deduct value

a. Retak kulit buaya

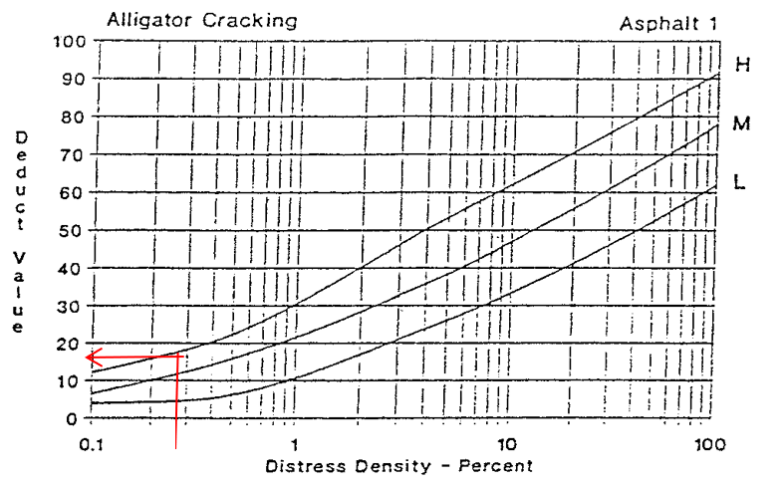

Gambar 5. Deduct Value Untuk retak buaya

Dari gambar 5 untuk jenis kerusakan retak kulit buaya dengan nilai Density 0,24\% dan High Savery Level, maka diperoleh nilai Deduct Value $=17$.

b. Lubang

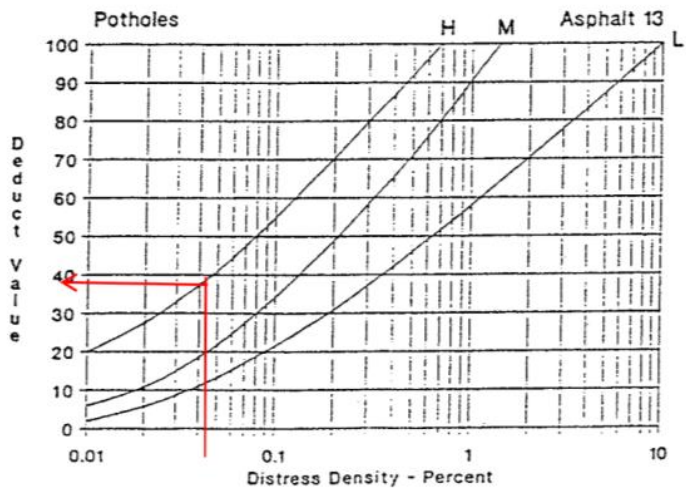




\section{Gambar 6. Deduct Value Untuk lubang}

Dari gambar 6 untuk jenis kerusakan Lubang dengan nilai Density 0,03 dan High Savery Level, maka diperoleh nilai Deduct Value $=35$.

Untuk hasil selengkapnya dapat di lihat pada uraian berikut:

1. STA $0+500 \mathrm{~s} / \mathrm{d}$ STA $0+600$

a. Retak Kulit buaya:

- Density $=0,24 \%$

- Deduct Value $=17$

- Total Deduct Value $=52$

- Corrected Deduct Value $=39$

- $\mathrm{PCI}=61$

- Kondisi perkerasan berdasarkan nilai PCI = Baik

b. Lubang:

- Density $=0,03 \%$

- Deduct Value $=35$

- Total Deduct Value $=52$

- Corrected Deduct Value $=39$

- $\mathrm{PCI}=61$

- Kondisi perkerasan berdasarkan nilai PCI = Baik

2. STA $0+600 \mathrm{~s} / \mathrm{d}$ STA $0+700$

a. Pelepasan Butir:

- Density $=0,23 \%$

- Deduct Value $=10$

- Total Deduct Value $=19$

- Corrected Deduct Value $=12$

- $\quad$ PCI $=88$

- Kondisi perkerasan berdasarkan nilai PCI = Sempurna

b. Tambal:

- Density $=0,16 \%$

- Deduct Value $=9$

- Total Deduct Value $=19$

- Corrected Deduct Value $=12$

- $\quad$ PCI $=88$

- Kondisi perkerasan berdasarkan nilai PCI = Sempurna

3. STA $0+700 \mathrm{~s} / \mathrm{d}$ STA $0+800$

a. Retak Pinggir:

- Density $=0,24 \%$

- Deduct Value $=11$

- Total Deduct Value $=43$

- Corrected Deduct Value $=33$

- $\quad \mathrm{PCI}=67$ 
- Kondisi perkerasan berdasarkan nilai PCI = Baik

b. Tonjolan dan Lengkung :

- Density $=0,11 \%$

- Deduct Value $=32$

- Total Deduct Value $=43$

- Corrected Deduct Value $=33$

- $\quad \mathrm{PCI}=67$

- Kondisi perkerasan berdasarkan nilai PCI = Baik

4. STA 0+800 s/d STA 0+900

Lubang:

- Density $=0,11 \%$

- Deduct Value $=58$

- Total Deduct Value $=58$

- $\quad$ Corrected Deduct Value $=56$

- $\mathrm{PCI}=44$

- Kondisi perkerasan berdasarkan nilai PCI = Sedang

5. STA 0+900 s/d STA $1+000$

Lubang:

- Density $=0,05 \%$

- Deduct Value $=39$

- Total Deduct Value $=39$

- $\quad$ Corrected Deduct Value $=38$

- $\mathrm{PCI}=62$

- Kondisi perkerasan berdasarkan nilai PCI = Baik

6. STA $1+000 \mathrm{~s} / \mathrm{d}$ STA $1+100$

Lubang:

- Density $=0,04 \%$

- Deduct Value $=39$

- $\quad$ Total Deduct Value $=38$

- $\quad$ Corrected Deduct Value $=38$

- $\mathrm{PCI}=62$

- Kondisi perkerasan berdasarkan nilai PCI = Baik

7. STA 1+100 s/d STA 1+200

Lubang:

- Density $=0,36 \%$

- Deduct Value $=80$

- Total Deduct Value $=80$

- Corrected Deduct Value $=81$

- $\quad \mathrm{PCI}=19$

- Kondisi perkerasan berdasarkan nilai PCI = Sangat Buruk 
8. STA $1+200 \mathrm{~s} / \mathrm{d}$ STA $1+300$

Pelepasan Butir:

- Density $=1,60 \%$

- Deduct Value $=15$

- Total Deduct Value $=15$

- Corrected Deduct Value $=16$

- $\quad \mathrm{PCI}=84$

- Kondisi perkerasan berdasarkan nilai PCI = Sangat Baik

9. STA $1+300 \mathrm{~s} / \mathrm{d}$ STA $1+400$

Tambal:

- Density $=0,43 \%$

- Deduct Value $=14$

- Total Deduct Value $=14$

- Corrected Deduct Value $=14$

- $\mathrm{PCI}=86$

- Kondisi perkerasan berdasarkan nilai PCI = Sempurna

10. STA $1+400 \mathrm{~s} / \mathrm{d}$ STA $1+500$

Lubang:

- Density $=0,10 \%$

- Deduct Value $=54$

- Total Deduct Value $=54$

- Corrected Deduct Value $=53$

- $\quad \mathrm{PCI}=47$

- Kondisi perkerasan berdasarkan nilai PCI = Sedang

Untuk nilai PCI perKilometer (KM) loakasi kajian adalah sebagai berikut:

PCI = Nilai PCI per Sampel : Banyak Sampel per Km

$\mathrm{PCI}=(61+88+67+44+62+62+19+84+86+47): 10$

$\mathrm{PCI}=62$.

Maka berdasarkan nilai PCI yang didapat pada ruas jalan Lambah Maninjau Kabupaten Agam STA $0+500$ s/d STA 1+ 500 di kategorikan Baik (Good) yang artinya bahwa perkerasan jalan atau jalan tersebut masih aman untuk di lalui kendaraan sesuai dengan ketetapan kondisi perkerasan yang berlaku.

\section{KESIMPULAN}

Berdasarkan hasil penelitian dan analisis yang dilakukan, maka diperoleh beberapa kesimpulan sebagai berikut:

1. Jenis kerusakan yang ada pada ruas jalan raya lambah maninjau Kabupaten Agam pada STA 0+500 s/d STA 1+500 adalah Retak Kulit Buaya, Lubang, Tambal, Retak Pinggir, Pelapukan dan Pelepasan Butir, Tonjolan dan Lengkungan.

2. Dari hasil perhitungan diperoleh nilai PCI sebesar 62 yang dikategorikan Baik 
(good).

Berdasarkan kesimpulan diatas maka penulis dapat memberikan sedikit saran agar kedepannya ruas jalan raya lambah maninjau Kabupaten Agam dapat lebih baik lagi, seperti:

1. Diperlukan pemantauan dan pengamatan kerusakan secara rutin, jika kemungkinan jalan rusak maka segera dilakukan perbaikan dengan metode perbaikan yang sesuai agar kerusakan dikemudian hari tidak bertambah luas.

2. Perlu dilakukan penelitian untuk memprediksi umur layan jalan berdasarkan hasil survei kondisi jalan.

3. Perlu dilakukan penelitian lebih lanjut mengenai penanganan terhadap kerusakan jalan yang terjadi.

\section{REFERENSI}

Andriyanto, Carto. 2010. Pemilihan Teknik Perbaikan Perkerasan Jalan Dan Biaya Penanganannya (Studi Kasus : Pada Ruas Jalan Nguter - Wonogiri). Skripsi tidak diterbitkan. Universitas Sebelas Maret. Surakarta

ASTM D6433. 2007. Standard Practice for Roads and Parking Lots Pavement Condition Index Surveys.

Budiyono, Mohammad. 2012. Analisa Kerusakan Jalan dengan Metode PCI dan Alternatif Penyelesaiannya (Studi Kasus: Ruas Jalan Purwodadi - Solo Km 12+000 - Km 24+000). Universitas Muhamadiyah Surakarta. Solo.

Departemen Pekerjaan Umum Jakarta Republik Indonesia. 2009. Undang-Undang No. 22 Tahun 2009 Tentang lalu lintas. Jakarta : Departemen Pekerjaan Umum.

Departemen Pekerjaan Umum. 1997. Manual Kapasitas Jalan Indonesia (MKJI), Direktorat Jendral Bina Marga, Jakarta.

Direktorat Jenderal Bina Marga, 1995, Manual Pemeliharaan Rutin Untuk Jalan Nasional dan Jalan Propinsi. Departemen Pekerjaan Umum, Direktorat Jenderal Bina Marga.

Direktorat Jenderal Bina Marga. 1995. Petunjuk Pelaksanaan Pemeliharaan Jalan Kabupaten. Petujuk T. Departemen Pekerjaan Umum. Direktorat Jenderal Bina Marga.

Dirjen Bina Marga. 1990. Panduan Survei dan Perhitungan Waktu Perjalanan Lalu Lintas. Departemen Pekerjaan Umum. Jakarta.

Hardiyatmo, H.C., 2007. Pemeliharaan Jalan Raya, Edisi-1. Gajah Mada University Press. Yogyakarta.

Hardiyatmo, H. C. 2015. Pemeliharaan Jalan Raya Edisi ke-2. Gadjah Mada University Press. Yogyakarta 
Idrus, M. 2011. Evaluasi kerusakan permukaan jalan dengan Metode Pavement Condition Index (PCI) pada ruas Jalan Insimu - Paguyaman. Fakultas Teknik Universitas Negeri Gorontalo. Gorontalo.

Irzami. 2010. Penilaian Kondisi Perkerasan dengan Menggunakan Metode Indeks Kondisi Perkerasan Pada Ruas Jalan Simpang Kulim - Simpang Batang. Tesis tidak diterbitkan. Universitas Islam Riau. Pekanbaru.

Shahin, M.Y., Walther, J.A. 1994. Pavement Maintenance Management for Roads and Streets Using The PAVER System. US Army Corps of Engineer. New York.

Sukirman, Silvia. 1999. Perkerasan Lentur Jalan Raya. Nova. Bandung. 